\title{
PROFIL PASIEN HIPERTENSI DI POLIKLINIK GINJAL-HIPERTENSI
}

\author{
${ }^{1}$ Marillyn M. Tamburian \\ ${ }^{2}$ Emma Sy. Moeis \\ ${ }^{2}$ Fandy Gosal \\ ${ }^{1}$ Kandidat Skripsi Fakultas Kedokteran Universitas Sam Ratulangi Manado
${ }^{2}$ Bagian Ilmu Penyakit Dalam Fakultas Kedokteran Universitas Sam Ratulangi Manado \\ Email : marillynmariana@gmail.com
}

\begin{abstract}
Hypertension is chrocnic medical condition which the blood pressure has elevated above $140 \mathrm{mmHg}$ systolic and $90 \mathrm{mmHg}$ diastolic. Hypertension is one of top 10 of the causes of death worldwide. It is because hypertension affects in damaged of some organs like heart, brain, renal, retinal, ect.The purpose of this study is to give the information about profile of hypertensive patients and about antihypertensive drugs which most commonly used in Prof. Dr. R. D. Kandou General Hospital Manado.This is descriptive retrospective study. The data had been taken from medical records in Nephrology and Hypertension Clinic at Prof. Dr. R. D. Kandou General Hospital Manado.
\end{abstract}

Keywords : Hypertension, Complication, Antihypertensive drugs

Abstrak : Hipertensi merupakan kondisi dimana tekanan darah sistol diatas $140 \mathrm{mmHg}$ dan tekanan darah diastol diatas 90 mmHg.Hipertensi menjadi salah satu penyebab kematian terbanyak didunia karena hipertensi dapat mempengaruhi kerusakan pada organ-organ target yang lain seperti organ jantung, otak, ginjal, mata dan lain-lain.Tujuan penelitian ini untuk memberikan gambaran tentang profil pasien hipertensi serta jenis obat antihipertensi yang digunakan di poliklinik ginjal-hipertensi RSUP Prof. Dr. R. D. Kandou Manado periode Oktober 2014 - Maret 2015.Penelitian ini merupakan jenis penelitian deskriptif retrospektif dengan data sekunder di poliklinik ginjal-hipertensi RSUP. Prof. Dr. R. D. Kandou Manado periode Oktober 2014 - Maret 2015. Sampel penelitian sebanyak 311 pasien.

Kata Kunci : Hipertensi, Komplikasi, Obat Antihipertensi

Hipertensi adalah salah satu penyebab kematian terbanyak didunia. Hipertensi merupakan naiknya tekanan darah sistol diatas $140 \mathrm{mmHg}$ dan tekanan darah diastol diatas 90 mmHg. 1

Menurut data World Health Organization (WHO) dan The International Society of Hypertension (ISH), saat ini terdapat 600 juta penderita hipertensi di seluruh dunia dan 3 juta diantaranya meninggal tiap tahunnya. Tujuh dari setiap 10 penderita tersebut tidak mendapatkan pengobatan yang adekuat. ${ }^{2}$ Prevalensi hipertensi di dunia pada usia diatas 18 tahun sekitar 22\% pada tahun 2014. ${ }^{3}$
Menurut Riset Kesehatan Dasar (Riskesdas) tahun 2013 di Indonesia prevalensi hipertensi yang didapat melalui pengukuran pada umur $\geq$ 18 tahun sebesar 26,5\%, tertinggi di Bangka Belitung (30,9\%), diikuti Kalimantan Selatan (30,8\%), Kalimantan Timur (29,6\%) dan Jawa Barat (29,4\%). Prevalensi hipertensi di Indonesia yang didapat melalui kuesioner terdiagnosis tenaga kesehatan sebesar 9,4 persen, yang didiagnosis tenaga kesehatan atau sedang minum obat sebesar 9,5 persen. Menurut jenis kelamin didapatkan prevalensi sebesar 6,0 persen laki-laki dan 4,7 persen perempuan. ${ }^{4}$ Di Sulawesi Utara prevalensi hipertensi berdasarkan pengukuran tekanan 
darah yaitu 27,1\% dan penderita yang sedang minum obat sebanyak $15,2 \% .^{3}$

Hipertensi terbagi atas hipertensi primer dan hipertensi sekunder. ${ }^{5}$ Hipertensi primer adalah hipertensi yang tidak diketahui penyebabnya sedangkan hipertensi sekunder adalah hipertensi yang diketahui penyebabnya seperti hipertensi renal atau hipertensi endokrin.Lebih dari 90\% hipertensi yang ada tidak diketahui penyebabnya atau hipertensi primer. ${ }^{6}$ Terdapat berbagai macam pedoman hipertensi di dunia. Pedoman yang saat ini dipakai adalah pedoman hipertensi dari Joint National Committee 8 (JNC 8). ${ }^{7}$

Hipertensi yaitu manifestasi gangguan keseimbangan hemodinamika sistem kardiovaskular, yang mana patofisiologinya adalah multi faktor sehingga tidak bisa diterangkan dengan hanya satu mekanisme tunggal. ${ }^{8}$ Mekanisme yang dikemukakan mencakup perubahan eksresi natrium oleh ginjal, kepekaan baroreseptor, respon vaskular dan sekresi renin. Apabila hipertensi terus dibiarkan, keadaan itu dapat menyebabkan gangguan pada organ-organ lain seperti jantung, otak, ginjal ataupun mata. ${ }^{9}$

Sebagaimana diketahui hipertensi adalah salah satu penyebab kematian terbanyak didunia yang dikarenakan hipertensi dapat mempengaruhi kerusakan pada organ-organ target yang lain seperti organ jantung, otak, ginjal, mata dan lain-lain. ${ }^{10}$ Maka dari itu, melihat berpengaruhnya hipertensi pada kerusakan organ dan faktor-faktor risiko yang ada serta banyaknya insiden hipertensi di Sulawesi Utara, penelitian ini dilakukan untuk mengetahui profil pasien hipertensi yang terkontrol dan tidak terkontrol serta penggunan obat antihipertensi di poliklinik ginjalhipertensi RSUP Prof. Dr. R. D. Kandou Manado periode Oktober 2014 - Maret 2015.

\section{METODE PENELITIAN}

\section{Jenis dan Desain Penelitian}

Penelitian ini adalah penelitian yang bersifat deskriptif retrospektif dengan data sekunder di poliklinik ginjal-hipertensi RSUP. Prof. Dr. R. D. Kandou Manado.

\section{Waktu dan Tempat Penelitian}

Penelitian telah dilaksanakan dari bulan Oktober-Desember 2015 di poliklinik ginjalhipertensi RSUP. Prof. Dr. R. D. Kandou Manado

\section{Populasi dan Sampel}

Populasi dalam penelitian ini adalah semua pasien poliklinik ginjal-hipertensi di RSUP. Prof. Dr. R. D. Kandou Manado periode Oktober 2014 sampai Maret 2015.

Sampel yang diambil yaitu penderita hipertensi yang datang ke poliklinik ginjalhipertensi dengan data yang lengkap.

\section{Variabel Penelitian}

Variabel dari penelitian ini yaitu: jenis kelamin, usia, komplikasi, penyakit penyerta dan terapi obat antihipertensi.

\section{HASIL PENELITIAN}

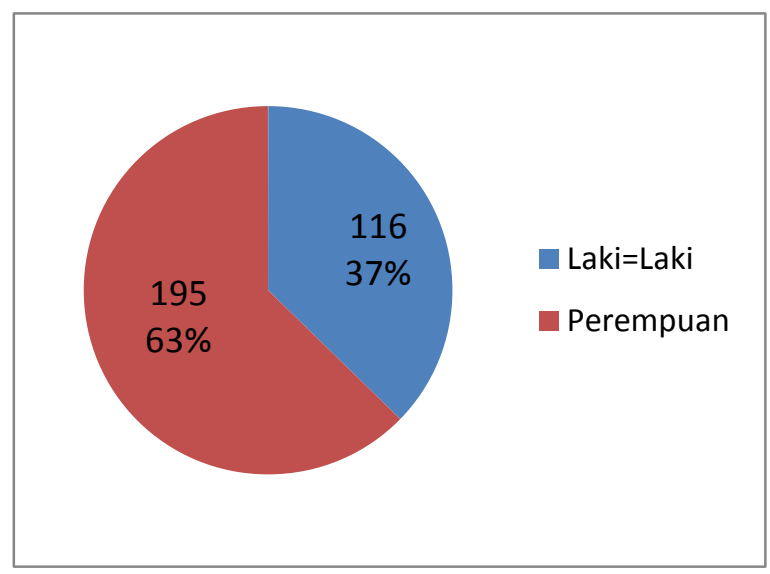

Gambar 1. Distribusi Pasien Hipertensi Berdasarkan Jenis Kelamin

Dari gambar diatas dapat dilihat bahwa dari 311 pasien terdapat 195 pasien perempuan dan 116 pasien laki-laki.

Berdasarkan hasil penelitian, ditemukan bahwa kelompok usia terbayak yaitu kelompok usia 60-69 tahun sebanyak 111 pasien. Kelompok usia 20-29 tahun sebanyak 4 pasien, 
30-39 tahun sebanyak 8 pasien, 50-59 tahun sebanyak 34 pasien, kelompok usia 50-59 tahun sebanyak 84 pasien, 70-79 tahun sebanyak 63 pasien dan 80-89 tahun sebanyak 7 pasien. Pasien termuda dengan umur 23 tahun dan yang tertua 86 tahun.

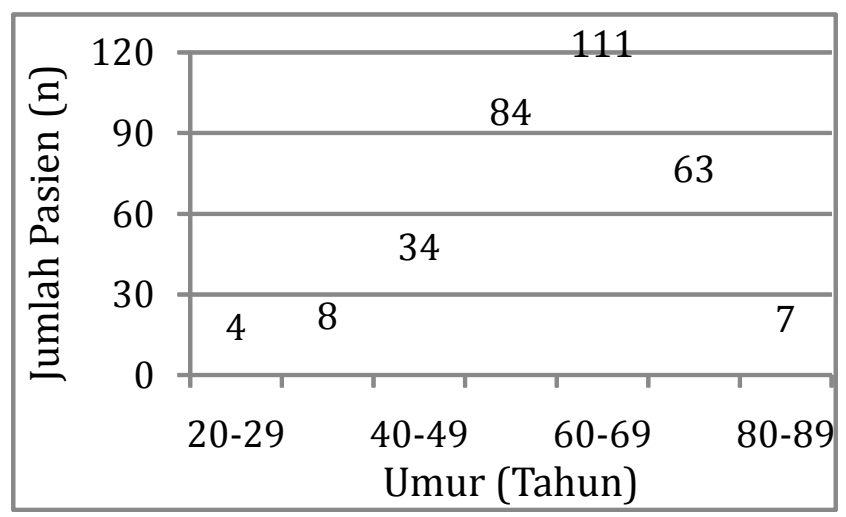

Gambar 2. Distribusi Pasien Hipertensi Berdasarkan Kelompok Umur

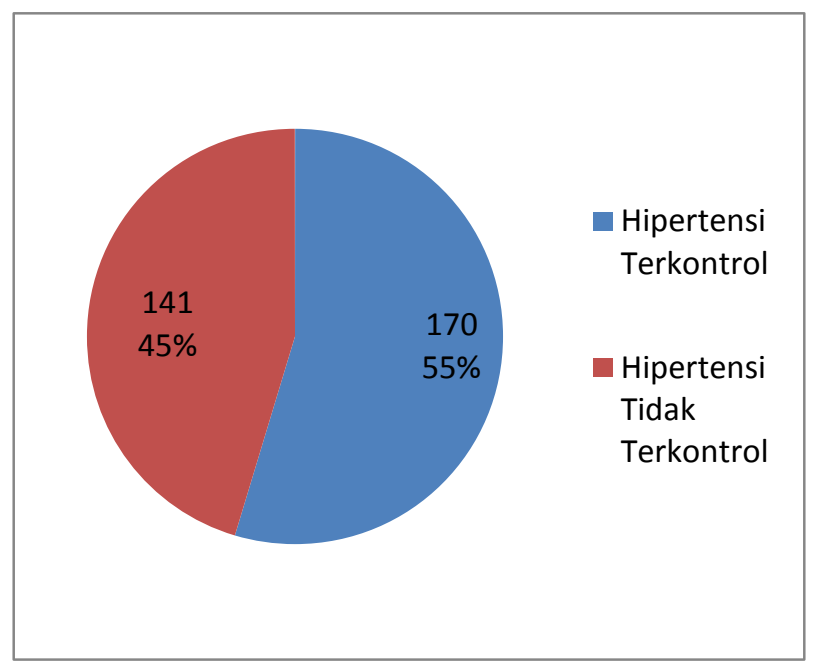

Gambar 3. Distribusi Pasien Hipertensi Berdasarkan Klasifikasi Hipertensi

Hasil penelitian dari Gambar 3 menunjukan bahwa 170 pasien ditemukan dengan tekanan darah yang terkontrol sedangkan 141 pasien ditemukan dengan tekanan darah yang tidak terkontrol.
Tabel 1. Distribusi Pasien Hipertensi Berdasarkan Komplikasi

\begin{tabular}{|c|c|}
\hline Komplikasi & Jumlah \\
\hline Tidak ada komplikasi & 183 \\
\hline PGK & 20 \\
\hline PGK + Retinopati & 5 \\
\hline PGK + Neuropati & 4 \\
\hline $\mathrm{PGK}+\mathrm{CHF}$ & 4 \\
\hline PGK + Demensia & 1 \\
\hline PGK + Retinopati + Neuropati & 4 \\
\hline PGK + Retinopati + CAD & 1 \\
\hline PGK + Retinopati + Kardiomegali & 1 \\
\hline PGK + Neuropati + CHF & 1 \\
\hline PGK + Retinopati + Neuropati + CHF & 1 \\
\hline $\begin{array}{l}\text { PGK + Neuropati + CHF + } \\
\text { Kardiomegali }\end{array}$ & 1 \\
\hline Retinopati & 35 \\
\hline Retinopati + Neuropati & 4 \\
\hline Retinopati + Kardiomegali & 3 \\
\hline Retinopati + CAD & 2 \\
\hline Retinopati + CHF & 2 \\
\hline Retinopati + Neuropati + CAD & 1 \\
\hline Neuropati & 18 \\
\hline Neuropati + CAD & 2 \\
\hline CAD & 6 \\
\hline CHF & 8 \\
\hline Kardiomegali & 4 \\
\hline
\end{tabular}

Keterangan : PGK (Penyakit Ginjal Kronis), CAD (Coronary Artery Disease), CHF (Congestive Heart Failure).

Tabel 1 menunjukkan kejadian komplikasi yang terjadi pada pasien hipertensi. Komplikasi yang paling banyak terjadi adalah 
retinopati dengan 35 pasien. Selain itu, terdapat 20 pasien yang menderita PGK, 18 pasien yang menderita neuropati, 8 pasien menderita CHF, 6 pasien menderita CAD dan yang sisanya mengalami komplikasi pada beberapa organ lain.

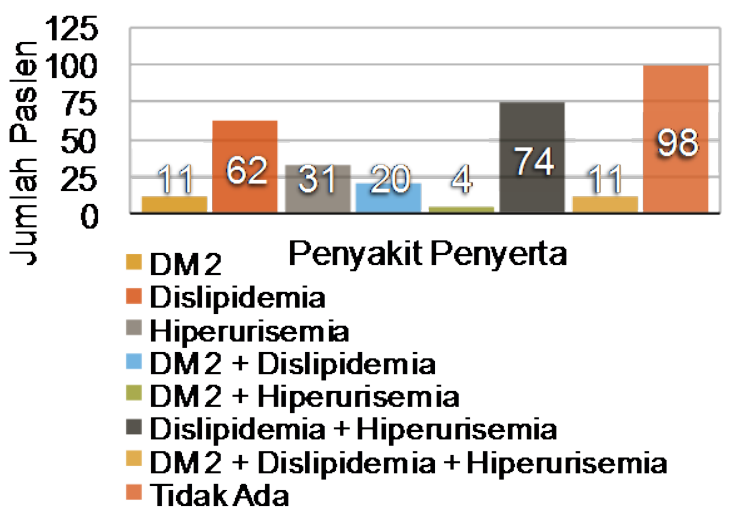

Gambar 4. Distribusi Pasien Hipertensi Berdasarkan Penyakit Penyerta

Dari gambar di atas dapat dilihat bahwa pasien tanpa penyakit penyerta sebanyak 98 pasien. Penyakit penyerta terbanyak ialah dislipidemia dan hiperurisemia yaitu sebanyak 74 pasien. 62 Pasien ditemukan dengan dislipidemia saja, 31 pasien ditemukan dengan hiperurisemia, 20 pasien dengan DM tipe 2 dan dislipidemia serta 11 pasien didapatkan dengan DM tipe 2.

Dalam menggunakan pilihan obat untuk terapi, terdapat 105 pasien hipertensi terkontrol menggunakan obat monoterapi sedangkan 65 pasien hipertensi terkontrol menggunakan dualterapi atau lebih. Pasien hipertensi yang tidak terkontrol yang menggunakan monoterapi sebanyak 65 pasien dan yang menggunakan dualterapi atau lebih sebanyak 76 pasien.
Tabel 2. Distribusi Pasien Hipertensi Berdasarkan Klasifikasi dan Pilihan Terapi

\begin{tabular}{llll}
\hline Terapi & $\begin{array}{l}\text { Hipertensi } \\
\text { Terkontrol }\end{array}$ & $\begin{array}{l}\text { Hipetensi } \\
\text { Tidak } \\
\text { Terkontrol }\end{array}$ & Jumlah \\
\hline Monoterapi & 105 & 65 & 170 \\
$\begin{array}{l}\text { Dualterapi / } \\
\text { lebih }\end{array}$ & 65 & 76 & 141 \\
Jumlah & 170 & 141 & 311
\end{tabular}

\section{PEMBAHASAN}

Berdasarkan penelitian yang dilakukan pada Oktober - Desember 2015 di RSUP Prof. Dr. R. D. Kandou Manado, didapatkan dari 311 pasien perempuan lebih banyak dari laki-laki. Hal ini menunjukkan kesamaan dengan penelitian sebelumnya yang dilakukan di tempat yang sama. Ada beberapa penelitian yang menunjukkan bahwa perbedaan hormon berperan dalam meningkatnya kejadian hipertensi pada perempuan terutama perempuan usia lanjut.

Pada distribusi hipertensi berdasarkan umur diketahui bahwa kelompok umur yang paling banyak adalah kelompok umur 60-69 tahun. Hasil ini menggambarkan bahwa usia merupakan faktor resiko dari hipertensi sesuai dengan pustaka yang ada. Keadaan ini dapat terjadi dikarenakan oleh beberapa hal, salah satunya adalah dengan lebih mudahnya terjadi arterosklerosis (penebalan dinding pembuluh darah) seiring dengan meningkatnya usia.

Dari hasil penelitian, dilihat bahwa 55\% pasien hipertensi yang telah menggunakan obat antihipertensi didapatkan dengan tekanan darah yang terkontrol sedangkan 45\% lainnya didapatkan dengan tekanan darah yang tidak terkontrol. Tekanan darah yang tidak terkontrol pada pasien hipertensi dengan obat mungkin disebabkan oleh pola hidup yang kurang baik, ketidaktaatan pasien dalam mengonsumsi obat ataupun kurang adekuatnya obat antihipertensi yang diberikan. 
Hipertensi dapat merusak beberapa organ target. Hasil ini memperlihatkan organ target yang paling sering diserang yaitu mata, ginjal, jantung dan otak. Organ tersebut yang sudah mengalami perubahan karena efek hipertensi dalam jangka waktu yang lama akan menyebabkan gangguan yang semakin parah.

Hasil distribusi berdasarkan satu penyakit penyerta dari hipertensi yaitu didapati 64 pasien dengan dislipidemia, 31 pasien dengan hiperurisemia dan pasien dengan DM tipe 2 sebanyak 11 pasien. Pasien terbanyak dengan lebih dari satu penyakit penyerta yaitu 74 pasien dengan dislipidemia dan hiperurisemia. Dislipidemia sangat erat kaitannya dengan hipertensi. Dislipidemia dapat menyebabkan disfungsi endotel yang berakibat pada hipertensi. Selain itu, hiperurisemia juga dicurigai berhubungan dengan hipertensi, sedangkan DM tipe 2 merupakan salah satu faktor resiko dari hipertensi.

\section{KESIMPULAN}

- Umur merupakan faktor resiko yang berperan terhadap kejadian hipertensi. Usia lanjut berisiko tinggi hipertensi dibandingkan dengan usia dibawahnya.

- $\quad$ Mengontrol tekanan darah dengan baik perlu dilakukan oleh pasien hipertensi.

- $\quad$ Komplikasi yang dapat disebabkan oleh hipertensi menyerang organ target seperti mata, ginjal, jantung dan otak. Efek dari komplikasi tersebut dapat dilihat dan dipantau melalui beberapa pemeriksaan.

- $\quad$ Penyakit penyerta dari hipertensi masih banyak ditemukan. Dislipidemia, hiperurisemia dan DM tipe 2 merupakan tiga diantaranya.

\section{SARAN}

- Perlunya edukasi terhadap pasien mengenai penyakit hipertensi dan bagaimana penanganannya.
- Edukasi kepada masyarakat tentang hipertensi dan pencegahannya guna mengurangi kejadian hipertensi.

- Penelitian selanjutnya dapat dilihat mengenai faktor-faktor resiko hipertensi yang lebih detail, penanganan serta pencegahan hipertensi, kajian keefektifan obat antihipertensi ataupun kepatuhan penggunaan obat antihipertensi guna membantu mengurangi angka kejadian hipertensi dan meningkatkan angka hipertensi yang terkontrol.

\section{DAFTAR PUSTAKA}

1. Joint National Committee. Complete Report The Seventh Report of the Joint National Committee on Prevention, Detection, Evaluation and Treatment of High Blood Pressure, 2004.

2. WHO-ISH Hypertension Guideline Committe. Guidelines of the Management of Hypertension. J Hypertension; 2003. 21(11). p. 1983-92.

3. WHO. Global Status Report on Noncommunicable Diseases 2014; 2014. p. 67-9.

4. Kementrian Kesehatan. Riset Kesehatan Dasar (RISKESDAS) 2013; 2013. h. 8890.

5. DiPiro J, Talbert RL, Yee G, Matzke G, Wells B, Posey LM. Pharmacotherapy: A Pathophysiologic Approach, 8th ed. Chapter 15: Hypertension. The McGrawHill Companies; 2011.

6. Longo DL, Kasper DL, Jameson JL, Fauci AS, Hauser SL, Loscaizo J. Harrison's Principles of Internal Medicine. 18th ed. New York: Mc Graw Hill; 2012. p. 2042-7.

7. JAMA. 2014 Evidence-Based Guideline for the Management of High Blood Pressure in Adult, Report From the Panel Members Appointed to the Eight Joint National Committee (JNC 8). 
8. Kaplan NM. Primary hypertension : pathogenesis. Kaplan's clinical hypertension. 10th ed. Philadelphia: Lippincot Williams \& Wilkins; 2010. p. 44-108.

9. Price SA, Wilson LM. Pathophysiology: Clinical Cencepts of Disease Processes. ed 6. vol 1. Elsevier Science; 2002. p. 585.

10. Withworth JA. World Health Organization International Society of Hypertension Writing Group. 2003 World Health Organization / International Society of Hypertension statement on management of hypertension. J Hypertens; 2003. p.198392. 